\title{
Educação das relações étnico-raciais na trajetória das lutas dos afro-brasileiros
}

\section{Education of ethnic-racial relations in the trajectory of Afro-Brazilian struggles}

\section{Educación de las relaciones étnico-raciales en la trayectoria de las luchas de los afro-brasileños}

Oswaldo de Oliveira Santos Junior*

\author{
Tem que acreditar. \\ Desde cedo, a mãe da gente fala assim: \\ "filho, por você ser preto, você tem que ser duas vezes melhor". \\ Ai, passados alguns anos, eu pensei: Como fazer duas vezes melhor, se você \\ tá pelo menos cem vezes atrasado pela escravidão, pela história, \\ pelo preconceito, pelos traumas, pelas psicoses... por tudo que aconteceu? \\ Duas vezes melhor como? \\ (A vida é um desafio - Racionais MC's)
}

\begin{abstract}
RESUMO
$\mathrm{O}$ artigo busca refletir a respeito dos processos que estimulam e favorecem a perpetuação do racismo no Brasil, ao mesmo tempo em que analisa as lutas sociais que buscam a promoção da igualdade racial e o combate ao racismo, compreendendo a lei 11.645/2008, que instituiu a obrigatoriedade do estudo da história e cultura afro-brasileira e indígena no ensino fundamental e no ensino médio, da rede pública e estabelecimentos privados, como parte deste processo de lutas de resistência e direito à memória e identidade.

Palavras chave: Etnia; educação; sociedade.
\end{abstract}

\begin{abstract}
This article reflects upon processes that stimulate and favour the perpetuation of racism in Brazil. At the same time, it analyses the social struggles that seek to promote racial equality and combat racism, considering the resolution 11.645/2008, which instituted the study of indigenous and Afro-Brazilians history and culture as obligatory school subjects for both elementary and high school, whether in public or private schools, as an outcome of processes of resistance struggles and claim for memories and identity rights.

Keywords: Ethnicity; education; society.

\section{RESUMEN}

El artículo pretende reflexionar sobre los procesos que estimulan y favorecen la perpetuación del racismo en Brasil, mientras que el análisis de las luchas sociales que buscan promover la igualdad racial y la lucha contra el racismo, incluyendo la Ley 11.645/2008, que establece el estudio obligatorio de la historia y la cultura afro-brasileña e indígena en la escuela primaria
\end{abstract}

* Mestre em Ciências da Religião pela Universidade Metodista de São Paulo (2007). Coordenador do Núcleo de Formação Cidadã da Universidade Metodista de São Paulo (UMESP). 
y en la secundaria, en las instituciones públicas y privadas, como parte de este proceso de luchas de resistencia y el derecho a la memoria y la identidad.

Palabras clave: Etnia; educación; sociedad.

\section{Introdução}

Não existe neutralidade no ato de educar. A prática docente implica, necessariamente, em escolhas e posicionamentos políticos por parte do educador e da educadora. Assim, ao refletir sobre a educação das relações étnico-raciais, é preciso ter clareza de que ela é parte de uma opção política de resistência às práticas pedagógicas que serviram - e ainda servem - para reproduzir a ideologia dominante, que silenciou a história e a cultura afro-brasileira, contribuindo, deste modo, para a sustentação do racismo e ampliação das formas de dominação e exploração.

Como observa Michael Löwy (2005, p. 65), ao analisar as teses "Sobre o conceito de História" de Walter Benjamin, "o pretenso historiador neutro, que aceita diretamente os fatos 'reais', na verdade apenas confirma a visão dos vencedores". A educação das relações raciais compreende, portanto, que o sujeito do conhecimento histórico é a própria população afrodescendente, que teve sua história brutalmente silenciada por séculos de opressão que ecoam no presente (BENJAMIN, 2005, p. 108).

Em sua tese de número VIII sobre o conceito de história, Walter Benjamin (2005, p. 83) afirma que "a tradição dos oprimidos nos ensina que o 'estado de exceção' em que vivemos é, na verdade, a regra geral. Precisamos construir um conceito de história que corresponda a essa verdade". A exploração, o racismo e a opressão da população afrodescendente ao longo da história não se constituem exceção, mas a regra, e tal situação precisa ser explicitada para que se possa edificar uma história do Brasil que corresponda, efetivamente, a todas as matrizes que constituem o povo brasileiro, estabelecendo, assim, a justiça.

Os estudos sobre a história dos afrodescendentes possibilitam a desconstrução da noção de progresso histórico de forma linear, ou seja, na "evolução das sociedades no sentido de mais democracia, liberdade e paz” (LÖWY, 2005, p. 83), o que contribui para uma perspectiva histórica crítica que desvela os processos de exploração que se apresentam como regra, e não exceção, ao longo da história, e que servem aos interesses da classe dominante, entendendo o racismo como um dos seus interesses. É possível compreender que a educação das relações étnico-raciais traz em seu bojo a "tarefa de escovar a história a contrapelo", isto é, não se propõe a reproduzir a história dos vencedores, mas, sim, a dos vencidos e oprimidos, para que as barbáries do racismo e da intolerância não se repitam (BENJAMIN, 2005, p. 70). 
A proposta deste texto é observar a relevância da lei 11.645/2008, que incluiu o estudo da história e cultura afro-brasileira e indígena nas escolas, compreendendo-a como parte de uma longa trajetória de lutas da população afro-brasileira para afirmação de sua identidade e memória, demostrando que a exploração e a violência racial têm sido a regra e não a exceção na história da sociedade brasileira.

Educação das relações étnico-raciais, componente da educação em direitos humanos

A educação em direitos humanos (EDH) possui um caráter de preservação, que se expressa em três características fundamentais. A primeira é a de ser uma "educação para o nunca mais", isto é, para que as práticas que violam os direitos humanos sejam explicitadas e não se repitam e se perpetuem na sociedade. Trata-se de romper com a cultura do silêncio e da impunidade. A segunda é a facilitação da compreensão e tomada de consciência de que todo indivíduo é "sujeito de direito". E a terceira dimensão é o "empoderamento" ("empowerment") deste sujeito (CANDAU, 2009, p. 71).

A educação em direitos humanos possui um objetivo político de transformação da realidade excludente e opressora. Ela se fundamenta em uma pedagogia da práxis, isto é, em uma "teoria de uma prática pedagógica que procura não esconder o conflito, a contradição, mas ao contrário, os afronta, desocultando-os" (GADOTTI, 2010, p. 28). É um processo que desnaturaliza as relações sociais baseadas na exploração e na desigualdade entre as pessoas, que não admite a invisibilidade social e o racismo, mas afirma a história dos grupos que sofreram processos de subalternização e negação da sua cultura, por meio das práticas do embraquecimento, como ocorreu com os afrodescentendes.

No prefácio da obra Pele negra, máscaras brancas, de Frantz Fanon (2008, p. 14), Lewis Gordon sustenta que, nos estudos sobre a questão do negro, há uma exigência neurótica de que estes estudos seriam sem conflitos se existisse o acordo de que o negro não existe. A tentativa de tornar a cultura afro-brasileira invisível ou de subalternizá-la persiste na sociedade brasileira e se constitui em um dos embates fundamentais da educação das relações étnico-raciais em sua luta contra o racismo e suas manifestações ardilosas.

A necessidade de afirmar a existência do negro em nosso contexto pode parecer exagero, contudo, é possível notar a insistência perversa do racismo escondido em gestos, olhares e expressões, ao mesmo tempo em que dominam as práticas de invisibilidade social em relação ao negro. A afirmação da existência do negro ocorre em oposição às manifestações que buscam negar a sua presença na sociedade, por meio, por exemplo, dos processos de embranquecimento e de desqualificação de sua cultura e história. 
Como afirma Frantz Fanon (2008, p. 95): “o negro não deve ser colocado diante deste dilema: branquear ou desaparecer, ele deve poder tomar consciência de uma nova possibilidade de existir", de existir como pessoa negra. É justamente em defesa de uma forma de existir que se articulam as lutas da população afro-brasileira desde o período colonial até os nossos dias, às quais se integra a educação das relações étnico-raciais.

Partindo desta premissa, é fundamental reafirmar a existência da mulher e do homem negro como sujeitos de direito e, também, o racismo enfrentado cotidianamente pela população afrodescendente. A afirmação da existência do negro se constitui em uma forma de insurgência e resistência contra os processos que geram a invisibilidade social e a estigmatização dos afrodescendentes, e deve integrar as políticas de ações afirmativas que visam à superação da discriminação racial e fundamentam os instrumentos legais e as políticas públicas.

É inegável que a questão racial é um componente a ser considerado nas relações sociais no Brasil, que se soma à questão de classe. Isto fica bastante evidente na análise dos dados estatísticos, como os apresentados no Mapa da Violência no Brasil (Waiselfisz, 2015), que apresenta, de forma contundente, a relação entre a cor e o número de homicídios no Brasil. É revelador que o Brasil se encontra diante de um verdadeiro genocídio da população jovem e afrodescendente, ou seja, o genocídio como uma prática social, um processo deliberado que encontra o consenso e o silêncio por parte da sociedade (FEIERSTEIN, 2014, p. 35-37).

Muito diferente do pensamento reafirmado no senso comum, a população afro-brasileira sempre esteve à frente dos processos de defesa da sua liberdade, e se posicionou como protagonista em sua história. A distorcida noção de subordinação dos negros, ou de uma pretensa apatia e aceitação da escravidão e outras formas de opressão, sempre se constituíram em ardis ideológicos a serviço de uma oligarquia sempre disposta a tudo para manter seus privilégios de classe. Isto nos faz pensar no fenômeno do racismo também sob o aspecto de dominação econômica.

A partir de uma aproximação com o pensamento de José Carlos Mariátegui (2008, p. 57), é possível compreender que a questão do racismo no Brasil decorre do equivocado conceito de raças inferiores, que teve como objetivo legitimar a conquista e a expansão colonial e, mais tarde, sustentar a maior expropriação do trabalhador do negro liberto, transformando as relações raciais em um componente a mais nas relações de exploração capitalista. No caso brasileiro, dizer que é social e não racial o preconceito que sofrem os afro-brasileiros é pura e simplesmente reprodução da ideologia dominante, que insiste na fábula da democracia racial. 
Falamos acima em discriminação racial, o que parece um equívoco, posto que, desde a década de 1940, a ciência tem demonstrado a inexistência de raças biológicas, isto é, que a variação genética dos seres humanos é irrelevante para se constituírem em diferentes raças. Contudo, se não se pode falar em "raças" humanas, é perfeitamente possível identificar que, nas relações sociais, a prática persiste, o que faz do racismo um fenômeno social e não biológico. Uma das formas como isto se dá é pelo processo de estigmatização.

\section{Resistência africana e afro-brasileira}

No Brasil, as formas de resistência contra a perversidade da escravidão foram as mais variadas, indo do suicídio às insurreições populares. A população negra escravizada jamais aceitou passivamente os grilhões que os prendiam. Ao longo de todo o período escravagista o que se viu foram homens e mulheres lutando por sua dignidade e liberdade. Essas lutas continuaram, mesmo após a abolição, em 1888, que, por sinal, não colocou um fim às práticas que sustentavam idelogicamente o sistema escravista.

A população negra escravizada no Brasil organizou uma das mais longas lutas sociais da história do continente, que permanece silenciada e invisível para milhões de brasileiros ainda hoje, o que indica a necessidade de refletir sobre estes fatos da história do Brasil.

As lutas dos povos africanos e seus descendentes no Brasil podem ser compreendidas em dois momentos: o primeiro, de 1530 a 1888; e o segundo, imediatamente após a abolição, em 1888, e que segue ainda hoje. Estes 358 anos (1530-1888) deixaram marcas que delinearam a sociedade brasileira, que se estruturou naturalizando o racismo e as práticas do embranquecimento, o que gerou uma dívida histórica com os afro-brasileiros. Como afirmou Fábio Konder Comparato (2008), “a escravidão de africanos e afrodescendentes no Brasil foi o crime coletivo de mais longa duração praticado nas Américas e um dos mais hediondos que a história registra”. Este crime coletivo inclui a negação da cidadania do direito à sua história e herança cultural.

Nesta trajetória de resistência, é importante destacar um marco fundamental na luta do movimento negro, no campo da educação, que é a lei 10.639/2003, que instituiu a obrigatoriedade da temática "História e Cultura Afro-Brasileira" e a lei 11.645/2008, que instituiu a obrigatoriedade do tema "História e Cultura Afro-Brasileira e Indígena". A estas leis se seguiram as Resoluções e Diretrizes que regulamentaram a matéria.

As leis, resoluções e diretrizes que tratam da educação das relações étnico-raciais devem ser compreendidas como parte de um longo processo de lutas dos afrodescendentes pelo direito à memória e identidade. 


\section{O estigma e a construção do "inferior racial"}

Erving Goffman (2008, p. 11-12) nos oferece uma importante contribuição para a compressão do fenômeno da estigmatização social. Recuperando o termo, surgido na Grécia antiga, onde estigma significava uma marca corporal que diferenciava um indivíduo, concedendo a este uma condição moral, estes sinais eram um aviso público, que o indivíduo levava consigo por onde fosse. $\mathrm{Na}$ Era Cristã, o termo passa também a ser usado no sentido metafórico, aplicado a certas situações tidas como sinais de desgraça e infortúnio.

As sociedades humanas elaboram formas de categorizar e hierarquizar os indivíduos, criando rótulos e estabelecendo atributos tidos como normais e anormais (GOFFMAN, 2008, idem). O racismo é resultado deste fenômeno, que estigmatiza, transformando o outro em um ser diminuído. Deste modo, "um indivíduo que poderia ter sido facilmente recebido na relação social quotidiana, possui um traço que pode se impor à atenção e afastar aqueles que ele encontra, destruindo a possibilidade de atenção para outros atributos seus" (GOFFMAN, 2008, p. 14).

O sujeito ou grupo estigmatizado passa a ser visto como não-humano e, em decorrência disto, surgem as discriminações, que reduzem as oportunidades de vida e o pleno gozo dos direitos. O estigma tribal (raça, nação, religião ou classe), do qual o racismo é um dos resultados, produz a negação da cidadania, ao reforçar o fenômeno do inferior racial e os insultos raciais (GOFFMAN, 2008; GUIMARÃES, 2002).

O insulto racial funciona como um instrumento de humilhação e "sua eficácia reside justamente em demarcar o afastamento do indivíduo que insulta em relação ao insultado, remetendo este último para o terreno da pobreza, da anomia social, da sujeira e da animalidade" (GUIMARÃES, 2002, p. 173). Todo processo de estigmatização se insere sempre na negação da humanidade do outro. Deste modo, a estigmatização da pele é, também, a negação da humanidade da mulher e do homem negro.

Dentre os estigmas que colaboram para a construção do negro como "inferior racial" encontram-se: "1. Uma pretensa essência escrava do negro; 2. A inclinação para a desonestidade e a delinquência; 3. A devassidão moral e sexual; 5. Uma irreligiosidade (ou uma forma de religiosidade associada ao mal); 6. A falta de higiene; e 7. A incivilidade, má-educação, e o analfabetismo" (Idem, p. 194).

Esta construção da inferioridade do outro passa por um processo de aprendizagem no qual estão envolvidos tanto o que produz a humilhação quanto o que é objeto dela. A linguagem é um dos meios pelos quais este 
processo ocorre, visto que "falar é estar em condições de empregar certa sintaxe (...) sobretudo assumir uma cultura, suportar o peso de uma civilização". A linguagem expressa, em grande medida, o mundo em que o indivíduo se situa. A sua fala diz muito do lugar que ele ocupa ou que é levado a ocupar na sociedade (FANON, 2008, p. 33-34).

No que tange à estigmatização racial no Brasil, ou seja, um dos fenômenos sociais que sustentam as práticas racistas, Antônio Guimarães (2002) classifica uma série de expressões que estão presentes na sociedade, conforme tabela a seguir:

\begin{tabular}{|c|c|}
\hline \multicolumn{2}{|r|}{ Insultos raciais / estigmas } \\
\hline Anomia Social & $\begin{array}{l}\text { - Estigma de delinquente: ladrão, folgado, safado, } \\
\text { traficante, etc. } \\
\text { Estigma de imoralidade: "vagabunda", "bastardo", } \\
\text { gigolô, etc. }\end{array}$ \\
\hline $\begin{array}{l}\text { Invocações de uma } \\
\text { natureza pervertida } \\
\text { ou de maldição } \\
\text { divina }\end{array}$ & $\begin{array}{l}\text { - Estigma de irreligiosidade ou perversão religiosa: } \\
\text { "Macumba", "Macumbeira", "maldito", "desgraça", } \\
\text { etc. }\end{array}$ \\
\hline Falta de higiene & $\begin{array}{l}\text { - Estigma da sujeira: "fedido", "podre", "porqueira", } \\
\text { etc. }\end{array}$ \\
\hline $\begin{array}{l}\text { Condição social de } \\
\text { inferioridade }\end{array}$ & $\begin{array}{l}\text { - "Favelado", "maloqueiro", "desclassificado", } \\
\text { "analfabeto", “metida" etc. }\end{array}$ \\
\hline Uso de diminutivos & • "negrinho", "negrinha" \\
\hline Animalização & - “macaco", "urubu”, “cadela”, "galinha”, etc. \\
\hline Doenças & - "queimada"; "cancerosa" \\
\hline
\end{tabular}

Fonte: GUIMARÃES, 2002, p. 175-176

Frantz Fanon (2008) também identificou uma linguagem (Petit-nègre) no tratamento do negro que incluía não somente o uso de diminutivos, mas, também, uma forma infantilizada de tratar com os negros na França. Conforme Fanon (2008, p. 44): "Não estamos exagerando: um branco, dirigindo-se a um negro, comporta-se exatamente como um adulto com um menino, usa a mímica, fala sussurrando, cheio de gentilezas e amabilidades artificiosas. Não observamos este comportamento em apenas um branco, mas em centenas...".

Esta linguagem, que beira certo paternalismo, acaba por humilhar e reforçar o estigma da pessoa negra como um ser primitivo e incapaz de uma comunicação no mundo tido como racional da sociedade branca, impõe uma barreira e delimita fronteiras entre os indivíduos e expressa a seguinte ideia em relação ao negro: "Você aí, fique no seu lugar!" (Ibid, p. 46). Esta 
questão se desdobra nas relações sociais entre brancos e negros. Frantz Fanon (Ibid, idem), ao analisar a sociedade francesa da década de 1960, faz a seguinte observação:

Encontro um alemão ou um russo falando mal o francês. Tento, através de gestos, dar-lhe as informações que ele pede, mas não esqueço que ele possui uma língua própria, um país, e que talvez seja advogado ou engenheiro na sua cultura. Em todo caso, ele é estranho ao meu grupo, e suas normas devem ser diferentes. No caso do negro, nada é parecido. Ele não tem cultura, não tem civilização, nem "um longo passado histórico". Provavelmente, aqui está a origem dos esforços dos negros contemporâneos em provar ao mundo branco, custe o que custar, a existência de uma civilização negra.

Ao negro é negada a sua história, cultura e civilização. Na sociedade brasileira, em que há certo encantamento com o estrangeiro, é comum observar pessoas que ostentam seus sobrenomes de origem europeia como sinal de distinção e status, como uma forma de pertença a uma cultura considerada "mais elevada".

\section{O racismo como mecanismo de legitimação da exploração}

Com a abolição da escravidão no Brasil (1888), a mão de obra imigrante (europeia) chega em grande contingente para a produção de café. Os negros libertos e os mulatos juntam-se ao contingente de trabalhadores livres, em uma economia de subsistência - pequenos trabalhos urbanos e o artesanato. Contudo, simultaneamente à abolição e à entrada dos imigrantes europeus, surge a ideia de que estes últimos são os trabalhadores por excelência: disciplinados, inteligentes, racionais e energéticos (FERNANDES, 2008).

Assim,

O negro e o mulato foram eliminados das posições que ocupavam no artesanato urbano pré-capitalista ou no comércio de miudezas e de serviços, fortalecendo-se, de modo severo, a tendência a confiná-los a tarefas ou ocupações brutas, mal retribuídas e degradantes (...) O impacto da competição com o 'estrangeiro' foi aniquilador para o negro e para o mulato (Idem, p. 41).

O processo de urbanização e crescimento econômico de base capitalista no final do século XIX no Brasil, e mais detidamente na cidade de São Paulo, trouxe consigo uma nova forma de exploração do trabalho do negro e do mulato, que teve no racismo um dos seus pilares, visto que o negro e o mulato passaram a ser considerados trabalhadores desqualificados, para os quais só cabe a disputa por trabalhos degradantes, humilhantes e precários. Nesta nascente sociedade de classes, o negro e o mulato não são vistos como 
"agentes naturais do trabalho livre e assalariado", estes são os imigrantes brancos. "O negro e o escravo eram pensados como categorias coextensivas. Conceitualmente, ser negro era ser escravo e ser escravo era ser negro" (CUNHA, 2012, p. 111).

Ao negro e ao mulato são deixadas as atividades degradantes e insalubres, como a de carregadores de café ${ }^{1}$ no porto do Rio de Janeiro, no final do século XIX. O trabalho era de tal modo penoso que a expectativa de tempo útil de trabalho nesta atividade era de apenas oito anos. Os trabalhadores chegavam a carregar mais de 72 quilos de café sobre a cabeça por aproximadamente mil metros, em um processo contínuo e extenuante (Idem, p. 116).

Como observa Florestan Fernandes, a construção social deste "inferior racial" ocorreu também porque "a sociedade brasileira largou o negro ao seu próprio destino, deitando sobre seus ombros a responsabilidade de se reeducar e de se transformar para corresponder aos novos padrões e ideais de ser humano, criados pelo advento do trabalho livre, do regime republicano e do capitalismo" (FERNANDES, 2008, p. 35-36).

No momento em que a sociedade brasileira passou por transformações nas relações de produção e o trabalho escravo foi substituído pelo trabalho livre, intensificou-se o processo de europeização da sociedade e o "descarte" da mão de obra negra e, para que este processo tivesse um ar de naturalidade e legitimidade, lançou-se mão da construção social do "inferior racial", o que contribuiu para perpetuar o racismo e intensificar as práticas de embranquecimento da sociedade.

A exclusão do negro e do mulato na sociedade de classes é somente aparente, visto que, na lógica da sociedade de classes, eles estão, de fato, inseridos, ou seja, não há exclusão social, mas uma inclusão ao processo de ampliação da exploração do trabalho no interior da ordem capitalista. A ideia de inferioridade do negro e do mulato frente ao trabalho livre e assalariado serviu como pretexto para a obra expansionista do capital.

É importante destacar que a perseguição e negação de trabalho ao negro liberto e também ao mulato têm início muitas décadas antes da abolição formal da escravidão, em 1888. Havia, no Brasil, desde a Revolução negra no Haiti (1792), um temor crescente de que poderia ocorrer no país algo semelhante. Exemplos não faltaram, como as revoltas dos nagôs (1826, 1828 e 1830) e, mais tarde, a Revolta do Malês (em 1835 - da qual falaremos adiante). Em decorrência deste medo, surge um arcabouço jurídico extremamente restritivo e que impede e dificulta o trabalho dos negros libertos, o que forçou

Este fato está registrado na gravura "Carregadores de café" de Edward Hildebrandt. Disponível em: http://www.exposicoesvirtuais.arquivonacional.gov.br/cgi/cgilua.exe/sys/start.htm?sid=102. 
a muitos retornarem para a África (CUNHA, 2012). Existem fortes indícios de que houve no Brasil a intenção, por parte da oligarquia dominante, de que a solução para a sociedade brasileira frente à questão dos negros fosse a deportação em massa da população negra para a África (Idem, p. 106-107).

Frente à sociedade de classes, restaram poucas oportunidades para o negro e o mulato no Brasil. A eles foi negada uma plena cidadania e a possibilidade de inserção no mercado de trabalho ou mesmo a proletarização. $\mathrm{O}$ que lhes restou foi incorporarem-se gradualmente ao operariado urbano mais precarizado ou "se abater penosamente, procurando no ócio dissimulado, na vagabundagem sistemática ou na criminalidade fortuita meios para salvar as aparências e a dignidade de homem livre" (FERNANDES, 2008, p. 44).

A compreensão destes processos históricos e sociais é fundamental para uma análise da sociedade contemporânea e das políticas de ação afirmativa, a exemplo das "cotas raciais", que buscam estabelecer marcos de reparação histórica. Nesta direção é que se encontra a Lei 11.645/2008, que estabelece a obrigatoriedade do estudo da história e cultura afro-brasileira e indígena no ensino fundamental e no ensino médio, da rede pública e estabelecimentos privados.

O percurso de lutas sociais até a Lei 11.645: o ensino de história e cultura afro-brasileira e indígena como medida de memória, justiça e verdade

O percurso das lutas por cidadania dos afrodescendentes no Brasil pode ser identificado em suas inúmeras formas insurgentes contra a escravidão e toda sua vilania. Os negros escravizados no Brasil organizaram uma das mais longas lutas sociais da história do continente americano, que permanece silenciada e invisível diante de milhões de brasileiros.

As lutas e as resistências dos povos africanos e seus descendentes no Brasil ocorreram em um longo período, estendendo-se de 1530 a 1888 , e seguindo até hoje. Estes 358 anos deixaram marcas que delinearam a sociedade brasileira, que se consolidou sobre o racismo e a cultura do privilégio, o que gerou uma dívida histórica com os afro-brasileiros que perdura até hoje.

Sabe-se que a história da população afro-brasileira, contada por meio dos livros didáticos, contos infantis e outros meios, ignorou fatos e processos históricos fundamentais e reforçou o senso comum reprodutor do racismo e discriminação. Nestes materiais, muitas vezes, o negro foi retratado como que aceitando a escravidão e submisso, ou mesmo que a única forma de integração à sociedade seria por meio da negação de sua negritude.

Contudo, de um modo diferente do que se leu e ouviu durante muitos anos, a população negra escravizada resistiu de inúmeras maneiras à violência da escravidão. Não houve submissão dos negros frente ao horror da escravi- 
dão; ocorreram lutas, resistências, suicídios e fugas. O aquilombamento, por exemplo, se configurou em uma das formas mais marcantes de resistência à escravidão no Brasil. Deste modo, é possível afirmar que, desde os primeiros momentos da escravidão negra, existiram processos de oposição a este violento ataque aos direitos mais fundamentais dos seres humanos: a liberdade de dispor do próprio corpo.

As lutas dos negros escravizados no século XIX são exemplos emblemáticos dos processos de resistência à escravidão negra no Brasil. Nota-se, ao longo de todo este século, uma série de movimentos que, por vezes, estão ligados uns aos outros e, em outros casos, são autônomos e circunstanciais. Assim, iniciando em 1807, com a "Revolta dos escravos", em Salvador; em 1815, com o "Ajuntamento de Pretos", em Olinda; entre 1830-41, “A Balaiada", no Maranhão, que inclui, além dos negros, os sertanejos pobres e indígenas; em 1835, o "Movimento Cabanagem", em Belém do Pará, que constituiu o primeiro e único governo de base popular (negros, indígenas e sertanejos) no Brasil; em 1835, “A Revolta dos Malês”, em Salvador, que foi a maior insurreição de negros escravizados de origem mulçumana ocorrida na história do Brasil; em 1838, ocorrem uma série de revoltas escravas no Brasil, desde o Maranhão até Minas Gerais, que foram responsáveis pela criação de inúmeros quilombos (GOHN, 2003).

Destas lutas de resistência contra a escravidão, merece destaque a "Revolta dos Malês" (1835). A Revolta foi marcada para iniciar no dia 25 de janeiro de 1835, no fim do Ramadã e início das festas de Nossa Senhora da Guia. "A previsão era que muito sangue correria, pois a intenção era libertar o maior número de negros possíveis, especialmente os mulçumanos, e matar brancos e também mulatos que considerassem traidores". Contudo, os insurgentes foram traídos e a revolta sufocada violentamente na véspera, levando à morte de 70 negros e 10 soldados, além de muitos presos e deportados (BENEDITO, 2006, p. 61).

Neste longo percurso de lutas por cidadania, chegamos ao dia 20 de novembro de 1995, quando cerca de 30 mil pessoas marcharam sobre Brasília e se posicionaram em frente ao Congresso Nacional. Durante mais de doze horas, militantes de diversos movimentos negros se uniram na busca por incluir na agenda política o tema do combate ao racismo que, até então, havia sido encoberto pela sociedade brasileira. Esta manifestação foi denominada Marcha Zumbi dos Palmares, contra o racismo, pela cidadania e pela vida.

No contexto da marcha, foi entregue ao então Presidente da República, Fernando Henrique Cardoso, o Documento da Marcha pelo presidente da Executiva Nacional da Marcha e do Movimento Negro Unificado (MNU), Edson Lopes Cardoso, em uma cerimônia organizada no Palácio do Planalto no dia 20 de novembro de 1995. 
O Documento da Marcha é uma síntese das discussões do movimento negro brasileiro naquele momento e aponta quais as reivindicações fazem parte de sua pauta central: a proposição de políticas públicas que atendam às necessidades da população negra e garantam a efetivação de sua cidadania. Ao mesmo tempo, o documento sinaliza os equívocos do mito da democracia racial brasileira.

É possível afirmar que a Marcha Zumbi dos Palmares, contra o racismo, pela cidadania e pela vida tenha sido um marco nas lutas da população afro-brasileira por seus direitos.

A partir desta reflexão, compreende-se que a Lei 11.645 - que instituiu o estudo de história e cultura afro-brasileira e indígena no ensino fundamental e médio - seja, ela mesma, parte de um longo processo de lutas pela expansão da cidadania. A própria lei, promulgada em 2003 (Lei 10.639), sofre um adendo que, para alguns estudiosos, é bastante controverso, ao incorporar, também, em 2008, a cultura indígena ao seu escopo. Como é possível observar abaixo:

\section{O PRESIDENTE DA REPÚBLICA}

Faço saber que o Congresso Nacional decreta e eu sanciono a seguinte Lei:

Art. 1ํ O art. 26-A da Lei no 9.394, de 20 de dezembro de 1996, passa a vigorar com a seguinte redação:

Art. 26-A. Nos estabelecimentos de ensino fundamental e de ensino médio, públicos e privados, torna-se obrigatório o estudo da história e cultura afro-brasileira e indígena. $\int 1^{\circ} \mathrm{O}$ conteúdo programático a que se refere este artigo incluirá diversos aspectos da história e da cultura que caracterizam a formação da população brasileira, a partir desses dois grupos étnicos, tais como o estudo da história da África e dos africanos, a luta dos negros e dos povos indígenas no Brasil, a cultura negra e indígena brasileira e o negro e o índio na formação da sociedade nacional, resgatando as suas contribuições nas áreas social, econômica e política, pertinentes à história do Brasil.

$\int 2^{\circ}$ Os conteúdos referentes à história e cultura afro-brasileira e dos povos indígenas brasileiros serão ministrados no âmbito de todo o currículo escolar, em especial nas áreas de educação artística e de literatura e história brasileiras.” (NR)

Art. $2^{2}$ Esta Lei entra em vigor na data de sua publicação.

Brasília, 10 de março de 2008; $187^{\circ}$ da Independência e 120 da República.

LUIZ INÁCIO LULA DA SILVA - Fernando Haddad. (BRASIL, 2008).

Como se observa, a lei 11.645 alterou a Lei 9.394/96, que trata das Diretrizes e Bases da Educação Nacional (LDB), ao incluir a obrigatoriedade do ensino de história e cultura afro-brasileira e indígena. Contudo, a lei não é o término da trajetória de lutas por direito e combate ao racismo.

Após dez anos de existência da lei, ainda há muito que se avançar no que diz respeito, por exemplo, à formação de professores para atuarem com 
esta temática e à compreensão de que não basta uma discussão "solta" no currículo escolar, mas, além disso, ações interdisciplinares e transversais.

As ações para implementação da Lei caminham, em muitos municípios, de forma lenta e desarticulada. Notam-se esforços da Secretaria de Políticas de Promoção da Igualdade Racial (SEPPIR), no sentido de articular as ações que favoreçam a implementação da Lei. Contudo, é certo que, não obstante a vontade política, continua sendo necessária a força de articulação dos movimentos sociais engajados na superação do racismo.

Estamos todos envolvidos em uma sociedade que transformou a hierarquização de seres humanos em uma prática corrente, como forma de manutenção do poder. É necessário, portanto, explicitar a insistência do racismo em nossa sociedade, visto que todos nós somos responsáveis pela construção de um mundo alicerçado nos ideais de justiça e solidariedade.

A Lei 11.645/2008, que instituiu a obrigatoriedade do estudo da história e cultura afro-brasileira e indígena no ensino fundamental e no ensino médio, da rede pública e estabelecimentos privados, deve ser entendida dentro de um marco histórico e social das lutas dos movimentos sociais na direção da expansão da cidadania e estreitamento dos privilégios. Contudo, a lei não encerra o processo, ela pontua e segue como referência para seguir lutando por direito e justiça.

Uma legislação que estabelece o ensino de história e cultura afro-brasileira tende a colaborar para a superação dos elementos que transformaram a discussão sobre o racismo em um tabu e as formas de branqueamento em medida de superação da questão: embranquecer os negros tornou-se o modo de integrá-los à sociedade e, assim, eliminar o preconceito.

No momento, o que se deseja, com uma educação que valoriza a história e a cultura afro-brasileira, é revelar a existência de um povo herdeiro de uma diversidade de culturas negras e que possui o direito de manifestar sua visão de mundo, suas crenças e seus gestos.

\section{Referências bibliográficas}

LÖWY, Michael. Walter Benjamin: aviso de incêndio - uma leitura das teses "Sobre o conceito de história”. São Paulo: Boitempo, 2005.

BENJAMIN, Walter. Sobre o conceito de história (1940). In: LÖWY, Michael. Walter Benjamin: aviso de incêndio - uma leitura das teses "Sobre o conceito de história". São Paulo: Boitempo, 2005.

BENEDITO, Mouzar. Luiz Gama: o libertador de escravos e sua mãe libertária, Luíza

Mahin. São Paulo: Expressão Popular (Col. Viva o povo brasileiro), 2006. 
BRASIL. Presidência da República. Lei no 11.645, de 10 de março de 2008. Disponível em: http://www.planalto.gov.br/ccivil 03/ ato2007-2010/2008/lei/111645.htm. Acesso em 05 de julho de 2017.

CANDAU, Vera. Educação em direitos humanos e diferenças culturais: questões e buscas. Revista Múltiplas Leituras, vol. 2, n. 1, p. 65-82, jan.-jun., 2009.

COMPARATO, Fábio Konder. Um débito colossal. Folha de São Paulo, 8 de jul. 2008, p. A3. CUNHA, Manuela Carneiro da. Negros, estrangeiros: os escravos libertos e sua volta à África. São Paulo: Companhia das Letras, 2012.

FANON, Frantz. Pele negra máscaras brancas. Salvador: Editora da UFBA, 2008.

FERNANDES, Florestan. A integração do negro na sociedade de classes. São Paulo: Globo, 2008.

FREYRE, Gilberto. Casa grande \& senzala: formação da família brasileira sob o regime da economia patriarcal. 50. ed. São Paulo: Global, 2005.

GOHN, Maria da Glória (Org.). Movimentos sociais no início do século XXI: antigos e novos atores sociais. São Paulo, Vozes, 2004b.

GOHN, Maria da Glória. História dos movimentos e lutas sociais: a construção da cidadania dos brasileiros. São Paulo: Loyola, 2003.

GUIMARÃES, Antonio Sérgio A. Classes, raças e democracia. São Paulo: Editora 34, 2006.

IANNI, Octavio. Língua e Sociedade. Caderno Primeira Versão, Campinas, n. 84, p. 9, 1999.

MARIÁTEGUI, José Carlos. Sete ensaios de interpretação da realidade peruana. São Paulo: Expressão Popular/CLACSO, 2008.

SCHWARCZ, Lilia Moritz. Nem preto nem branco, muito pelo contrário: cor e raça na sociabilidade brasileira. São Paulo: Claro Enigma, 2012.

Submetido em: 8-5-2017

Aceito em: 5-6-2017 